\title{
Los intelectuales argentinos y España: de la Generación del '37 a Ricardo Rojas
}

\author{
María Rosa LoJO ${ }^{1}$ \\ CONICET-Universidad de Buenos Aires-Universidad de El Salvador
}

\begin{abstract}
RESUMEN
Deseoso de convertir al país donde había nacido en una nación moderna similar a Francia o Inglaterra, Sarmiento fustigó el analfabetismo, la sumisión al poder clerical, y todo lo que consideraba "atraso" en cualquiera de sus manifestaciones heredadas de la Madre Patria.

No era, desde luego, la excepción, entre los intelectuales que constituyeron la llamada "Generación del '37". Hija de los que guerrearon por la Independencia política, fue la constructora y gestora del proyecto nacional triunfante después de la caída de Juan Manuel de Rosas y llevó adelante una empresa de emancipación cultural en busca de otro perfil identitario.

No obstante, no todo fue antihispánico en la construcción de una cultura argentina. Como en tantas otras cosas, los escritores Lucio y Eduarda Mansilla supieron dar la nota de equilibrio. Por otra parte, pronto surgieron dos motivos poderosos que propiciaron una creciente revaloración de lo hispánico. Uno de ellos, era la aluvional inmigración de otros orígenes y otras lenguas. El otro, el inquietante avance de los Estados Unidos hacia una hegemonía continental.

En este contexto de mayor atención y consideración por la herencia española, cabe situar la obra de Ricardo Rojas, joven intelectual en la época del primer centenario, que llevaría a cabo una intensa reivindicación de la raíz hispánica, así como una instalación de la raíz aborigen en el imaginario de una Argentina que prefería ocultarla y olvidarla. Su obra recupera el legado de la Generación del '37, pero repone en él los elementos ibéricos que el fervor independentista y la veneración por Francia habían dejado de lado u oscurecido.
\end{abstract}

Palabras clave: intelectuales argentinos, España, distanciamiento, emancipación lingüística, Generación del '37, Ricardo Rojas, búsqueda identitaria.

\section{Argentine Intellectuals and Spain: the Generation of '37 Ricardo Rojas}

\begin{abstract}
Eager to turn his natal country into a modern nation similar to France or England, Sarmiento strongly disapproved of analphabetism, clerical power submission, and everything that he considered "backward" in any of the manifestations inherited from the Mother Land.

He was certainly not the exception amongst the intellectuals that belonged to the so-called "Generación del '37'. Heiress of those who fought for political independence, this generation

\footnotetext{
${ }^{1}$ Investigadora Principal del CONICET-Universidad de Buenos Aires-Universidad de El Salvador.
} 
was the ideologist and promoter of a national project that became successful after the downfall of Juan Manuel de Rosas, and carried out an enterprise of cultural emancipation in search of a new identity profile.

However, not everything was anti-Spanish in the construction of the Argentinean culture. Like in many other things, the writers Lucio and Eduarda Mansilla were able to reach equilibrium. In addition, soon arouse two powerful reasons that encouraged an increasing revalorization of Hispanic roots. One of them was the massive immigration from other places and languages. The other one, the disturbing pace of the United Sates of America towards becoming a continental hegemony.

In this context of more attention and consideration for the Spanish heritage, we can situate the work of Ricardo Rojas, a young intellectual around the first centenary of the revolution, who would carry out an intense vindication of the Hispanic roots, as well as the "resetting" of the aboriginal roots in the Argentinean imaginary, where they had been deliberately hidden and forgotten. His written works recover the legacy left by "Generación del '37", but also reset the Spanish elements that the independence fervor and the veneration for French culture had left aside and obscured.

Keywords: Argentinean intellectuals, Spain, distance, linguistic emancipation, "Generación del '37", Ricardo Rojas, identity search.

SUMARIO: 1. El "voluntario distanciamiento de España" y sus matices. 2. Ricardo Rojas: España como interlocutora permanente, 2.1. Vida y obra, 2.2. España, la raíz viva, 2.3. España, la contemporánea, 2.4. Una demolición del estereotipo negativo.3. Bibliografía.

\section{El "voluntario distanciamiento de España" y sus matices}

En el artículo "Gallegos de aquende y de allende" ( 6 de enero de 1884), el escritor, político y pedagogo Domingo Faustino Sarmiento, sostiene, brutalmente, que los españoles debieran estarles agradecidos a los argentinos, españoles americanos, porque éstos les presentan un espejo empeorado de sus mismos vicios, y salvan así a España de ser la "última nación del mundo civilizado" (1928: 245).

El duro juicio, además de atacar, en primer término, a sus connacionales, no sólo se refería, claro, a los gallegos de Galicia (sus antepasados por vía paterna), sino a los peninsulares en general, englobados en el gentilicio del grupo etnocultural español más numeroso en la Argentina. Tal postura tajante no era nueva en el autor de Facundo. Mucho antes de ostentar cargos políticos, cuando viajaba por Europa comisionado por el gobierno de Chile para estudiar los sistemas educativos, ya pontificaba, indignado: "Opino porque se colonice la España" (1993: 166).

Deseoso de convertir al país donde había nacido en una nación moderna similar a Francia o Inglaterra, Sarmiento fustiga el analfabetismo, la sumisión al poder clerical, lo que considera "atraso" en cualquiera de sus manifestaciones heredadas de la Madre Patria.

No era, desde luego, la excepción, entre los intelectuales que constituyeron la llamada "Generación del '37". Hija de los que guerrearon por la Independencia política, fue la constructora y gestora del proyecto nacional triunfante después de la 
caída de Juan Manuel de Rosas y llevó adelante una empresa de emancipación cultural en busca de otro perfil identitario. En este sentido, señala Borges, "nuestra historia es también la historia de "un querer apartarse de España", de "un voluntario distanciamiento de España" (1974: 267- 274).

Uno de sus miembros más brillantes y precoces, el jurista y ensayista Juan Bautista Alberdi, enunció tempranamente, en las reuniones del Salón Literario de Marcos Sastre, una declaración de Independencia que comprometía la cultura toda de la nueva nación y en particular, las bases mismas de la identidad lingüística ${ }^{2}$. Colocó, por lo demás como modelo, no ya heredado, sino libremente elegido en un gesto de autonomía, el paradigma francés:

Si una lengua no es otra cosa que una faz del pensamiento la nuestra pide una armonía íntima con nuestro pensamiento americano, más simpático mil veces con el movimiento rápido y directo del pensamiento francés que no con los eternos contorneos del pensamiento español. [...] El día que dejamos de ser colonos, cayó nuestro parentesco con la España: desde la República, somos hijos de la Francia. (1984: 153)

Nuestra lengua aspira a una emancipación, porque ella no es más que una faz de la emancipación nacional, que no se completa por la sola emancipación política [...] El pueblo fija la lengua, como fija la ley; y en este punto ser independiente, ser soberano, es no recibir su lengua sino de sí propio. (1984: 154-155)

El crítico literario, filólogo y erudito por antonomasia de esta misma generación: Juan María Gutiérrez, llegó a darse el lujo de rechazar, en 1876, el diploma de miembro correspondiente de la Real Academia Española. Las razones en las que fundamentó su declinación de tal honor son harto elocuentes. Los argentinos, argumenta, no pueden velar por la pureza de la lengua castellana como si fueran españoles de Castilla. Por el contrario, se han emancipado de España y -abiertos a las múltiples migraciones no sólo de otros pueblos ibéricos como el catalán o el gallego, sino de toda Europa- son verdaderos mestizos culturales. Ese mestizaje, lejos de ser "contaminante" resulta fecundo y moviliza "el pensamiento libre", arguye el polemista. "El pensamiento - dice- se abre por su propia fuerza el cauce por donde ha de correr, y esta fuerza es la salvaguardia verdadera y única de las lenguas, las cuales no se ductilizan y perfeccionan por obra de gramáticos, sino por obra de los pensadores que de ellas se sirven" (2006: 420). La sujeción a la lengua del otro (del otro que fue antiguo amo), concluye Gutiérrez, puede convertirse en peligrosa sujeción política, sometiendo al académico americano a las opiniones, también conservadoras, que profesan sus pares de la Península. Anticipándose al Borges de "El escritor argentino y la tradición", reclama para los hispanoamericanos y los

${ }^{2}$ No obstante -señala José Luis Moure (2008)- Alberdi, en su madurez, adopta una actitud más moderada que su compañero Gutiérrez. Le objeta la devolución del diploma académico español y él mismo acepta un nombramiento como académico correspondiente. 
argentinos en particular, nada menos que el patrimonio entero de la tradición universal.

A su vez, el poeta y mentor ideológico del '37, Esteban Echeverría, propone, y encarna en su propia poética, nuevos paisajes (el "desierto" autóctono) y nuevos modelos estéticos (los románticos, franceses o alemanes, a través de traducciones francesas) que conoce en su "viaje iniciático" al Viejo Mundo (sobre todo a París) y que difunde en la Argentina. Pero no por eso desea desprenderse de "lo mejor de la tradición literaria española", sino más bien, afirmarse en ella (Myers: 68); en ese sentido, toma distancia de las posiciones más claramente rupturistas de otros contemporáneos. Revolucionario de las ideas y de los tópicos literarios, de las formas de la sensibilidad, Echeverría, con todo, es quien más parece resistirse, de hecho, al divorcio lingüístico en sus opciones léxicas y sintácticas (Myers: 57)

Al decir de Unamuno, el propio Sarmiento, crítico recalcitrante del atraso español, se encoleriza con España con la pasión de un nativo (idea que retomará -véase infraRicardo Rojas) y lo hace en una espléndida prosa castiza: "es más español que ninguno de los españoles, a pesar de lo mucho que habló mal de España. Pero habló mal de España muy bien" (Unamuno: 196). Félix Weinberg no deja de señalar, por su parte, la marcada influencia que ejercieron sobre la generación romántica los integrantes de la llamada "Joven España": esos autores que también en la Península abogaban por la renovación y la libertad. Polemistas y literatos como Larra, Espronceda, Meléndez, Quintana, Zorrilla (Weinberg: 68-69), así como los liberales españoles (Jovellanos) incidieron en los primeros gestores de la Independencia.

No todo es antihispánico después, en la cultura argentina que se quiere moderna. Como en tantas otras cosas, los escritores Lucio y Eduarda Mansilla supieron dar la nota de equilibrio. Políglotas y cosmopolitas, fueron también orgullosamente criollos. Capaces de hablar, de vivir y de escribir en francés, pero defensores del español. Lectores omnívoros de una tradición universal que incluía, en lugar privilegiado, los grandes clásicos castellanos.

En una posición equidistante tanto del vasallaje lingüístico y cultural como de la lejanía indiferente, Lucio V. Mansilla propone, en las postrimerías del siglo XIX, la creación de un diccionario fiel tanto al habla peninsular como a las nuevas voces americanas, que "se vendería desde Méjico a Tierra del Fuego como pan bendito" (1963: 482) y que "no por ser español dejaría de ser americano" (486). Una lengua castellana ampliada (con atención a sus diferentes dialectos extra muros) es lo que Mansilla sustenta como bien común de españoles e iberoamericanos que comparten no sólo un idioma sino un temperamento idiosincrátrico: "teniendo nosotros sangre española y hablando lengua española (más o menos bien), hemos de tener ideas españolas más o menos agallegadas" (480). Su balance, en suma, es positivo, a favor del legado ibérico: "no hay nación que yo ame más que la España ni lengua que me guste más que la española; porque es tan clara y tan precisa como la lengua inglesa, y tan armoniosa y tan bella como el mismo italiano. La primera vez que yo dije "te amo" fue en esta lengua." (485)

Aunque Mansilla siempre había profesado estas convicciones (por algo afirma en "Los siete platos de arroz con leche" que a los veinte años volvió de su primer viaje a 
Oriente y a Europa sin afrancesamientos lingüísticos, "potro americano hasta la médula de los huesos" -1963: 94-), la coyuntura finisecular hacía que aun los antihispanistas revisaran la dureza de antiguas posturas. Inclusive Sarmiento, cuando cree advertir en la creciente inmigración más "espíritu de factoría" que de verdadero arraigo y comienza a temer por una "Babel lingüística" que sea también una "Babel de banderas" (Sarmiento, 1928: 417-424; Lojo, 2007: 288). El viejo Mansilla, lanzado a escribir sus Memorias, se lamenta: "El gaucho simbólico se va, el desierto se va, la aldea desaparece, la locomotora silba en vez de la carreta; en una palabra, nos cambian la lengua, que se pudre, como diría Bermúdez de Castro, el país" (1954: 65).

El panorama de fin de siglo es, sin duda, complicado. Para las corrientes del positivismo y el darwinismo social que dominarán la escena de las ideas en sus últimas décadas, las razas aborígenes son las peor conceptuadas. Pero los latinos del Viejo Mundo (sobre todo italianos y españoles) no cosechan precisamente elogios. Los "modelos de civilización" vigentes reconocen su cumbre en los sajones (Gran Bretaña, los Estados Unidos de Norteamérica), tanto en lo intelectual como en lo ético. Para el viejo Sarmiento de Conflicto y armonía de las razas en América, para el educador positivista Agustín Álvarez, la tradición hispánica está en la raíz de los males argentinos (Biagini: 49-51, 99).

No obstante, hay dos motivos poderosos que propician una creciente revaloración de lo hispánico. Uno de ellos, al que ya aludimos, es la aluvional inmigración de otros orígenes y otras lenguas. Ésta empieza pronto a generar todo tipo de alarmas, trasladadas a los debates parlamentarios, sobre la eventual gestión autonómica (una suerte de "estado dentro del Estado") que podrían llegar a desenvolver algunas de estas colectividades, en particular, la italiana (Lojo, 2007: 287-288), que ya contaba con escuelas y diarios propios. Otro factor percibido como inquietante es el avance de los Estados Unidos hacia una hegemonía continental. El ensayo Ariel (1900), del uruguayo José Enrique Rodó, se proyecta sobre ambas orillas del Río de la Plata como emergente más notorio de toda una tendencia cultural, prohijada por el modernismo, que mira con recelo al nuevo bárbaro Calibán (potencial invasor) representado por los americanos del Norte.

Los festejos del cuarto centenario del Descubrimiento, en 1892, habían dado lugar, por lo demás, al recrudecimiento de fervores hispanistas y a la atenuación (oficial) de viejas beligerancias (por ejemplo, la supresión de las estrofas del Himno Nacional Argentino más ofensivas para España, así como la promulgación del día 12 de octubre como feriado nacional). Las activas instituciones culturales de las colectividades hispanas y los muchos intelectuales y profesores españoles radicados en la Argentina salieron a combatir la minusvaloración de lo hispánico. El clima de debate y de rescate se había instalado y para el primer centenario de la Revolución de

${ }^{3}$ Apunta Hugo Biagini que en las tesis racistas del positivismo en expansión "Hasta se les llegó a asignar, a los españoles, una capacidad craneana y un coeficiente antropométrico muy por debaje del de los habitantes del centro y norte de Europa, lo cual colocaba a aquéllos en una posición intermedia entre el caucásico y el negro" (Biagini: 99). 
Mayo, en 1810, a pesar de la "galolatría" (Biagini) que seguía caracterizando a las élites, la actitud hacia la Madre Patria, que había enviado como aplaudida representante a la Infanta Isabel de Borbón, era sin duda más amable y conciliadora.

En este contexto de mayor atención y consideración cabe situar la obra de Ricardo Rojas, joven intelectual en la época del primer centenario, que llevaría a cabo una intensa reivindicación de la raíz hispánica, así como una instalación de la raíz aborigen en el imaginario de una Argentina que prefería ocultarla y olvidarla (Lojo, 2004). Su obra recupera el legado de la Generación del '37, pero repone en él los elementos ibéricos que el fervor independentista y la veneración por Francia habían dejado de lado u oscurecido.

\section{Ricardo Rojas: España como interlocutora permanente}

\section{Vida y obra}

Ricardo Rojas nació en Tucumán, en el Noroeste argentino, en 1882, y se educó en la vecina provincia de Santiago del Estero (de donde procedían su padre y abuelos paternos), desde 1884 a 1898. Se trasladó luego (1889) a Buenos Aires, para iniciar estudios de Derecho que quedaron truncos: su vasta formación humanística sería una obra de autodidacta. Trabajó en el periodismo, en la docencia secundaria y luego en la universitaria (Universidad de La Plata, 1908). En 1903 publicó un primer libro de poesía: La victoria del hombre, y se integró al grupo de la revista Ideas, fundada por Manuel Gálvez y J. Olivera, donde se vinculó con jóvenes intelectuales que compartían su búsqueda de una tradición nacional, basada, para ellos, en las raíces hispano-criollas, que la élite cultural anglófila y francófila, prefería desconocer o dar por superadas. Su viaje a Europa en 1907-1908 le aportó los elementos para escribir La restauración nacionalista (1909), libro que despertaría polémicas. También para otros libros que giran en torno a Europa, y dentro de ella, en torno a la herencia hispánica. Se trata de El alma española (1908) y Cartas de Europa (1908). Treinta años más tarde, en 1938, Retablo español vuelve sobre la experiencia de esa estadía juvenil en España con renovado y meditado interés.

A partir de 1909, a su retorno, desarrolló en el país una obra ingente en la investigación, el pensamiento y la creación literaria. Fue miembro de las Academias de Letras y de Historia, rector de la Universidad de Buenos Aires, donde inauguró una Cátedra y un Instituto dedicados a la literatura nacional. A él se debe la Historia de la Literatura Argentina concebida de una manera sistemática. Su casa -cifra de su estética eurindiana, mezcla de elementos hispánicos y precolombinos- es hoy, por su donación, uno de los museos de esta ciudad. En 1930, Rojas, que no había tenido actuación política partidaria, se sumó a la Unión Cívica Radical, después de haber sido destituido el presidente constitucional Hipólito Yrigoyen, líder del radicalismo, por un golpe de Estado ${ }^{4}$. Sufrió la persecución del régimen militar y fue encarcelado

${ }^{4}$ El 6 de setiembre de 1930, durante la segunda presidencia constitucional de Hipólito Yrigoyen (que había asumido en octubre de 1928), se produce un golpe de Estado militar, 
en Ushuaia; allí continuó escribiendo. Una vez liberado regresó a la enseñanza universitaria, pero renunció a sus cátedras y a la dirección del Instituto de Literatura Argentina en 1946, por disidencias con el gobierno peronista. Murió en Buenos Aires el 19 de julio de 1957.

\section{España, la raíz viva}

Para Rojas, ante todo, el ser humano no existe en abstracto: pertenece siempre a una tierra, a una "raza" (en un sentido espiritual, no biológico ${ }^{5}$ ), a una comunidad vinculada por una memoria, una tradición, una cultura. El reconocimiento de esta pertenencia es imprescindible para que los individuos y los pueblos accedan plenamente a la dimensión humana, entendida como dimensión espiritual; la pertenencia no inhibe la libertad, pero hay que contar con ella para ejercerla (Rojas, 1924: 93). Esta concepción se expone y desarrolla, en relación concreta y particular con la Argentina, en sus primeros libros de ensayo sobre la cuestión nacional: $L a$ restauración nacionalista (1909), que exhorta a superar la mentalidad utilitaria de la "factoría" cosmopolita para rescatar los fines espirituales de la "nación" y Blasón de plata (1910), que apela al poder "numénico configurante" (genius loci) de una matriz telúrica e indiana. Ambas obras se inscriben en los fuegos cruzados entre "nacionalistas" y "cosmopolitas" (Bertoni) que en realidad prolongan, en la década del Centenario de la Revolución de Mayo, una polémica de ya larga data en la sociedad. Estos libros constituyen una respuesta al sentimiento de disgregación social y pérdida de especificidad cultural (y hasta de soberanía nacional) que experimentaba buena parte de la opinión pública argentina, no solamente algunos grupos minoritarios, ante las oleadas inmigratorias provenientes de todos los puntos del planeta: la pluralidad étnica, lingüística y cultural parecía difícilmente controlable y asimilable por un país nuevo y aún no firmemente consolidado. Rojas sintetiza y representa esa tendencia, desde un pensamiento idealista vinculado con el romanticismo alemán (Fichte, y sus Discursos a la nación alemana), con la generación del '98 española, con el krausismo, con el "arielismo" de Rodó, sin desdeñar las influencias teosóficas, necesarias para comprender la construcción simbólica de su obra, además de los autores franceses que manejó habitualmente su generación (Fustel de Coulanges, Taine, Renan). No obstante, mantuvo total

liderado por el general José Félix Uriburu, que asume como presidente provisional, condena la política, persigue y reprime a los opositores y descarta la democracia representativa, a la que pretende reemplazar por un sistema de representación corporativo. Cabe señalar que Uriburu pronto desilusiona a algunos sectores nacionalistas antiliberales que lo habían apoyado, y restaura el antiguo régimen conservador del llamado "liberalismo oligárquico".

5 "En un sentido histórico, es un fenómeno espiritual, de significación colectiva, determinado por un territorio y un idioma, o sea por un ideal. Según esto, los individuos, cualesquiera sea su procedencia, obran en función de un grupo histórico, ya sea éste el de origen u otro de adopción" (Rojas, 1980: I, 100).

${ }^{6}$ Cfr. el excelente análisis de Leonor Arias Saravia (364-403). La expresión citada es de la p. 413. 
conciencia de las inevitables diferencias entre Europa y Latinoamérica en cuanto a la formación de las nacionalidades ${ }^{7}$ y el contenido de los nacionalismos. Cuidó muy bien de distinguir su concepción nacionalista y el nacionalismo argentino, de "sus homónimos de las otras naciones" ${ }^{\prime}$. De ahí que sea injusto considerarlo como un epígono de Barrès, o como un pensador "protofascista". Tanto en sus ideas explícitamente declaradas como en su conducta sostuvo siempre principios republicanos y democráticos.

¿Supuso la concepción nacionalista de Rojas una idea cerrada y excluyente de la tradición argentina? No pueden negarse el fuerte acento defensivo y las alarmadas hipérboles de sus dos libros iniciales. Tampoco puede ignorarse su esencialismo metafísico, su voluntad de legitimar lo nacional desde un origen que determinaría $a b$ initio los rasgos de la "argentinidad" entendida como una identidad pre-constituida in nuce, que se va desenvolviendo en "avatares", como los llama Rojas, a lo largo de una Historia traspasada por fines que trascienden a los invididuos. Pero al menos, ese origen ya es doble: es "Eurindia". El elemento nativo precolombino no está muerto, no es un fósil arrumbado en los sótanos de la memoria, sino un sustrato activo, que ha fascinado y trastocado al conquistador, que ha actuado en una historia común, y que sigue operando en la sociedad argentina. La vieja dicotomía "civilización/barbarie" es reemplazada por otra: "exotismo/indianismo" (donde lo antes llamado "bárbaro" es lo legítimamente autóctono y propio), pero no se busca descartar uno de sus términos sino comprender a ambos como corrientes constitutivas de una nueva configuración espiritual sintética. La mirada se vuelve hacia las provincias, para revalorar su papel en la independencia y en la gestación de la nación-estado y de la nacionalidad (en tanto comunidad axiológica y cultural), ensanchando y corrigiendo, provocativamente, la interpretación historiográfica proveniente del liberalismo rioplatense. Incluso su retorno a la tradición española es -en el contexto de época- un gesto renovador. Supone aceptar otra raíz profunda que, junto con la raíz aborigen, las élites argentinas habían negado. Aunque por esos años se celebraba el Centenario de la Revolución de Mayo, Rojas reivindica el aporte español positivo, por sobre los elementos de opresión y aniquilación. Por momentos sus descripciones se exaltan con ciertos tintes mesiánicos: "Vino a nosotros -dice del conquistador- por designio providencial, no a demoler nuestro pasado, sino a abreviarnos el plazo del porvenir", "Vedle como una fuerza de vida, como un huracán del destino, como un transmutador del espíritu, que vino a sustituir un ídolo por otro ídolo, un verbo por otro verbo, un

${ }^{7}$ Las enumera muy detalladamente en La guerra de las naciones (96 y ss.).

${ }^{8}$ Desde el inicio, Rojas se defiende de la asimilación de sus propias ideas a las de pensadores franceses, como Maurice Barrés, de quien se hizo derivar su obra (1971: 47). A pesar de las fundamentadas denegaciones de Rojas, se lo siguió considerando un epígono de Barrés, como puede verse en el artículo de Oscar Massota (146-147). Cabe señalar, además, que el Rojas de 1930 considera el golpe militar y la Dictadura de Uriburu como lamentables resultados de un superficial espíritu de imitación de las ideas fascistas entonces en boga en Europa, sin atender ni a la tradición ni a la coyuntura histórica argentina. 
jefe por otro jefe, todo para un alto designio" $(1954: 86)^{9}$. Tanto el antihispanismo como el antiindianismo - considera- han sido dos extravíos de la autoconciencia argentina. Amigo personal de Ramiro de Maeztu, corresponsal asiduo de Unamuno, lector entusiasta de Ganivet (de cuyo "espíritu territorial" sin duda es deudor) Rojas cree, con ellos, en la importancia de recuperar para el presente una herencia hispánica aún viva.

Su gran obra de estética: Eurindia (1924), se propone describir la constitución y la evolución de una cultura desde lo que para Rojas es su fruto más representativo y eminente: el arte. No se trata ya sólo de la Argentina, sino de toda América (aun la anglosajona), considerada como una pan-nación nacida del mestizaje cultural hispano-indígena. De todas maneras, estima que la América Hispana puede superar en cuanto a "genialidad creativa" a la América del Norte. Si Rojas está siempre dispuesto a admitir y a admirar los aportes de los Estados Unidos en materia de instituciones democráticas ${ }^{10}$ e incluso educativas, previene contra la hipertrofia tecnológica y economicista que podría atrofiar la vida espiritual de esta nación (1960: 40), a la que en algún momento llama "hermano mayor". Encuentra, para todas las artes americanas, cuatro etapas generales, cuatro expresiones: indígena o primitiva, colonial o española, cosmopolita o europea, patricia o nacionalista, parangonables a las que ha hallado en la historia de la literatura argentina ${ }^{11}$, y que subsistirían en la sincronía "aisladas o refundidas", "armónicas o antagónicas" (Eurindia, 1980: II, 72). La estética expuesta no es una preceptiva apriorística, "no propone leyes claustrales para el arte ni para la patria". Sí es, en cambio, prospectiva: "se emancipa también el arte con la esperanza de nueva belleza": la que América puede agregar a lo que Europa le ha enseñado (1980: II, 78).

En su múltiple actividad como docente e investigador, Rojas nunca cesó de ocuparse del legado hispánico. Dejó estudios sobre clásicos españoles y ediciones anotadas, escribió sobre la época colonial en Hispanoamérica, y en Argentina especialmente. Entre todas estas obras, cabe destacar, sin duda, su Cervantes (1935), elaborado en circunstancias muy particulares, durante su prisión política en Ushuaia, entre enero y mayo de 1934. Aparte de que se dedica a desacreditar en esta obra ciertos lugares entonces comunes de la crítica cervantina (como la tesis del "ingenio lego", o la falta de valor de la poesía del autor del Quijote) su trabajo trasciende los fines de una meditación académica. Cervantes se convierte, para el preso, en un paradigma humano con quien se identifica. Así como él había resistido la prisión

${ }^{9}$ Hoy, en el contexto de la discusión del etnocentrismo, y luego de los festejos del V Centenario, sería difícil hablar con tanta seguridad del "alto designio". Pero cabe aclarar que Rojas, contra la posición dominante de su época, reivindicó la herencia aborigen tanto como la española, y consideró que lo "indiano" daba su sello y singularidad indeleble a la nueva cultura mestiza.

${ }^{10}$ Dejó esto bien sentado en La guerra de las naciones (1924: 278).

${ }^{11}$ Cada tomo corresponde a una etapa: Los gauchescos (1917), Los coloniales (1918), Los proscriptos (1920), Los modernos (1922). 
desde la escritura creadora, Rojas la resiste escribiendo sobre Cervantes. El escudo de la portadilla que ostenta su libro reproduce el de la primera edición del Quijote con su lema "Post tenebras spero lucem".

Cabe apuntar que la primera plana de la intelectualidad española había redactado una carta, dirigida al gobierno de facto, para solicitar la liberación de Ricardo Rojas. Ésta se produjo antes de que la carta fuese enviada, pero el escritor argentino tuvo de todas maneras la satisfacción de recibirla como testimonio de amistad. Habían firmado, entre otros, figuras como Ramón Menéndez Pidal, Pedro Salinas, Juan Ramón Jiménez, Gregorio Marañón, Américo Castro, Ramón Gómez de la Serna, Luis Giménez de Asúa. La carta fue publicada como parte del apéndice de su libro cervantino.

\section{España, la contemporánea}

Pero Rojas no sólo vio a España en sus clásicos, o las figuras guerreras o místicas de los fundadores que aparecen en sus ensayos, y que le inspiraron obras de teatro, como el conquistador don Diego de Rojas (presunto antepasado) en Elelín o el hidalgo donjanuesco de La Salamanca. La vio también como una cultura contemporánea con la que la Argentina podía y debía entablar un diálogo de interés mutuo. Dos de sus libros, sobre todo, condensan esta actitud. Uno de ellos es El alma española (1907), que da cuenta de su fascinación por España y de sus lecturas españolas, y que une, desde la dedicatoria, el pasado de América con el presente de España. Dice así: "A la memoria de los primeros conquistadores de América y a la obra de los nuevos escritores de España". El espectro de autores peninsulares de los que se ocupa es muy amplio, desde el punto de vista ideológico y estético: Núñez de Arce, Blasco Ibáñez, Pompeyo Gener, Pérez Galdós, Baroja, Echegaray, Rueda, Dicenta. Sus adhesiones más personales están por aquellos que -como Blasco Ibáñez- se han comprometido en una empresa de "regeneración" nacional (sin duda afín a su propia empresa naciente de "regeneración argentina"): el atraso, la superstición, el patrioterismo, el autoritarismo, el catolicismo sombrío que impide el goce de la naturaleza y de la vida, el poder clerical, son todas rémoras de las que España debiera desprenderse para recuperar su grandeza creadora. Y los artistas que se están ocupando de ello son preferentemente, no los castellanos, sino los que provienen de las provincias, de las regiones donde se hablan también otras lenguas: vascos, gallegos, catalanes (1907: 85); del mismo modo espera Rojas que la renovación llegue desde las provincias argentinas.

El hispanismo de Rojas no es regresivo ni prescriptivo: no propone el retorno nostálgico a la España conquistadora de la cruz y de la espada; al contrario, señala que los tiempos han cambiado y que ya no sirven para ella "las condiciones místicas y guerreras de su antiguo vivir"; pero aquilata lo hispánico en la tradición y el idioma. Sostiene, además, que ese legado alcanza su expresión y transformación más original 
y revulsiva, no en un español peninsular, sino en un hijo de las ex colonias: Rubén Darío, "representante genuino del alma de nuestra América" (1907: 211) ${ }^{12}$

El otro libro de Rojas sobre España, Retablo español (1938) tiene la peculiaridad de haber sido publicado veinte años después de que su autor recogiera las anotaciones sobre las cuales este libro se basa. La perspectiva del tiempo le da a los textos (o cuadros) del "retablo" una profundidad singular. La España de comienzos de siglo se lee a partir de su presente, enlutado por la Guerra Civil, que es, como lo dice el propio autor, el gran desencadenante de este mismo libro ${ }^{13}$ :

Acaso sea la aflicción de la actual tragedia lo que ha avivado mis recuerdos, moviéndome a escribirlos el contraste de aquellos días con los de hoy, y la propia necesidad de entender lo que allá ocurre, aunque yo no trato de la España actual sino de la España histórica. Estas páginas nacen de un viejo amor, hoy dolorido. (8-9)

Los conflictos que estallaron luego se avizoran allí en ciernes, muchas reflexiones resuenan como profecías, otras, como deseos y esperanzas incumplidas. Los jóvenes de 1908 son hombres maduros veinte años después; alguno ha muerto trágicamente, como Ramiro de Maeztu. Pero para Rojas, siempre atento a las invariantes, el "alma española" no ha cambiado, y entenderla es, para los argentinos, fundamental, "porque su historia es parte de la nuestra" (1938: 9).

Desde el principio, Rojas aclara que su mirada no ha sido, ni podrá ser, la del extranjero. Él no se ha sentido extranjero a España, ni los españoles lo han considerado tal. El "antiespañolismo" argentino, sostiene, es una falsa posición que viene, en muchos casos, de la frivolidad, el esnobismo, la pedantería cosmopolita (17). Es un pecado de superficie (341), nacido del desconocimiento, propio de las clases medias y altas progresistas que consideran a España como parte de África, extremo bárbaro de Europa (338 y ss.): "Un europeísmo superficial, un concepto equivocado de la civilización, una idea más equivocada aún de nuestra propia raza y su destino habían deformado durante medio siglo la educación, la política y hasta el

12 Rojas dedica aquí varias parrafadas a defender a Darío de todas las acusaciones de artificiosidad y antiamericanismo que por entonces se le hacían. Demuestra, por el contrario, lo que debe al espíritu progresista americano, a la singularidad criolla y aun al atavismo indígena. Rojas fue discípulo y amigo del poeta nicaragüense, y lo defendió ante Unamuno. La influencia modernista se advierte, desde luego, en su poesía (sobre todo en Los lises del blasón, 1911).

${ }^{13}$ Recordemos que por estos mismos años, entre el 36 y el 39, comienzan a llegar a la Argentina, fundamentalmente a raíz de la diáspora republicana, artistas, intelectuales y políticos españoles que publicarán libros y fundarán editoriales, así como científicos de todas las ramas que enriquecerán las universidades: Francisco Ayala, Eduardo Blanco Amor, Ramón Gómez de la Serna, Alejandro Casona, Manuel Colmeiro, Francisco Balaguer, Juan Cuatrecasas, Isaac Pacheco, Antonio Bonet, Ernesto Vilches, María de Maeztu, María Teresa León, Rafael Alberti, Luis Santaló, Arturo Cuadrado, Manuel de Falla, Maruja Mallo, Elena Fortún, Luis Jiménez de Asúa, Rafael Dieste, entre tantos otros. 
arte en nuestros pueblos" (341). En el caso de Sarmiento, cruel, más que injusto, con España - dice- no habría sido el desapego lo que lo llevó a la crítica lapidaria, sino, por el contrario, la furia del que ama aquello que critica y se indigna ante sus carencias y defectos precisamente porque lo siente propio. Por otra parte, sostiene, el "mal español" no puede adjudicarse al pueblo, sino a un Estado mal dirigido por dinastías extranjeras desde los mismos Habsburgos, comenzando por Carlos V que tronchó las libertades populares (44-45). Frente las posturas historiográficas propensas a identificar a España sólo con la Inquisición y el oscurantismo, Rojas reivindica, en sus obras de historiador (como La Argentinidad, 1916) a los cabildos de Hispanoamérica como origen autóctono de la democracia argentina, anterior a las ideas de la Revolución Francesa. El sentido igualitario, la orgullosa libertad del individuo, son una herencia española antes que gálica. El "genio ibérico" oprimido, sostiene, "se evade en América o en el arte" (48). No deja de señalar el autor, ya avanzado el libro, la influencia del liberalismo gaditano, con las legendarias Cortes Constitucionales de 1812, en los independistas americanos. Recuerda que la palabra "liberal" justamente, nació en Cádiz, y que la revolución española fue sofocada por la Santa Alianza. Mientras que España, durante la era napoléonica, es salvada por las Juntas Populares, el indigno Fernando VII, una vez repuesto, traiciona los deseos del pueblo. Por ello también en Argentina, afirma, el ideario antiespañol aparece recién en la segunda generación independiente, por rechazo hacia la política de Fernando VII (340).

No se le oculta a Rojas la dificultad de aislar o discriminar "lo español" en una nación hecha de varias naciones y de varias lenguas, invadida incontables veces, y cuyo mapa étnico es diverso en la diacronía y en la sincronía. No obstante, se empeña en descubrirlo (muy de acuerdo con su mitología y su poética personal) a la manera de quien realiza un "viaje iniciático" (una "peregrinación esotérica", 103, que esta vez no es a París), una incursión en los "Misterios". Y el "misterio español" es una pertinaz, irreductible originalidad, que la distingue tanto de Europa como del África: "Es una ínsula ibérica - dice- distinta de cuanto la rodea" (11). Y al final del libro insistirá: "España es el problema y España la solución" (357).

Habría un "ser espiritual" que se mantiene, como un eje, traspasando los múltiples sedimentos étnicos y culturales. Rojas lo encuentra ya en los iberos, "sobrios, austeros e indomables en la guerra" (29) donde se moldea el "ser o tipo espiritual" que sigue emergiendo en la España visible. Unamuno -uno de los "maestros" presentados en esta crónica de personajes, ciudades y monumentos- es descrito como un "ibero labrando a golpes su hacha de sílex" (68). Menéndez y Pelayo es una emanación del genio ibérico, individualista, excesivo, tenaz (95). Santa Teresa, "una sacerdotisa ibérica en quien se manifiesta el módulo espiritual más recóndito de la raza", "revelación del genio ibérico, ascético y personal [...]" (190). Considera a las Moradas y al Quijote como los dos libros más representativos del "misterio español" (190). Un realismo de alta expresividad que sabe vincular lo sublime y lo vulgar, lo terreno y lo celeste, aún en el arte sacro, le parece el sello estético de España, así como ve en el heroísmo persistente durante más de dos mil años (176) su sello ético. Sin negar la especificidad etno-cultural de las regiones españolas, Rojas encuentra en 
ellas ese "eje espiritual" y considera, por lo demás, que la solución política y económica se halla en una Federación genuina con intereses comunes en la que coexistan las lenguas locales con una lengua oficial compartida (anticipándose así en décadas al devenir político de la España democrática). El separatismo, de Vasconia o de Cataluña -opina- redundaría en beneficio de Europa, pero no de las regiones que desean separarse ni del resto de España (330-332). Trata, por otro lado, de defender a Castilla contra las acusaciones de las otras regiones: catalanes que la juzgan atrasada, gallegos que la consideran opresora. Reconoce, sí, una mala fundación del antiguo estado español, que no atiende a la justicia nacional. Se empeña en distinguir de ese "estado central" al pueblo castellano, que padeció igualmente los abusos de los señores, y cuyo aporte necesario es sobre todo "espiritual", antes que económico y tecnológico.

Por todas partes, Rojas va descubriendo los hilos culturales que se mantienen entre España y Argentina: un cantar de ciego escuchado en Madrid le recuerda los romances gauchescos (71); las aldeanas de Ávila hablan con los arcaísmos del Martín Fierro (88); unas coplas que ha incluido en El país de la selva como típicas de Santiago del Estero resultan ser coplas sevillanas (100). Los vínculos aparecen hasta en el paisaje y la vestimenta, como es el caso de Sevilla, cuya tierra, y cuyos paisanos, a caballo y con guitarra, lo remiten, otra vez, a Santiago (116). ¿No habrá también -se pregunta- un ida y vuelta, una fuerte influencia indiana en esta ciudad? Los jinetes moros, cuando baja a Tánger, le parecen gauchos (como le parecieron a Sarmiento, que además se jactaba de su ascendencia árabe por el lado materno).

En cada ciudad visitada (de La Coruña a Granada, de Burgos a Barcelona, de Ávila a Córdoba), el cuadro trazado por el autor toma en cuenta la historia, la arquitectura y el paisaje, tanto el natural como el paisaje humano. Rojas pasa también revista al estado de las artes. Halla que los mejores pintores de la actualidad (Zuloaga, Anglada, Sorolla, Romero de Torres) no están en los museos; encuentra deficiencias en la música (la gran escuela moderna de música española -Albéniz, Pedrell, Falla, Turina, aún no estaba del todo formada, ni era difundida). En la arquitectura no ve una personalidad genuinamente propia, aunque no deja de elogiar, en Barcelona, el arte innovador de Gaudí (321). Su gran interés, desde luego, es literario. En el retablo se dibujan perceptivos retratos de escritores españoles: además de los ya mencionados, Galdós (cuyo genio Rojas, entonces poeta modernista, admite haber reconocido en plenitud veinte años después), Blasco Ibáñez (al que confiesa apreciar más de lo que lo apreciaban sus colegas contemporáneos), Valle Inclán, Benavente, de Maeztu, Ganivet, Pardo Bazán, de la que traza un interesantísimo perfil: la describe como una escritora original, distinta de todas las demás literatas españolas de la época, que trabaja, con éxito, en campos y géneros tenidos hasta entonces como exclusivamente varoniles. Es la primera en crear en España, "con su predicación y con su obra una conciencia feminista" (298). Sin embargo, la condesa fallecerá con el disgusto de no haber logrado entrar a la Academia de Letras, un puesto que ambicionaba -señala Rojas sagazmente-"acaso no por vanidad, sino como conquista de su credo", por "deseo de abrir una brecha feminista en la ciudadela de los doctos ancianos, casi todos conservadores" (301). No faltan otros retratos de 
hispanoamericanos en España: el escéptico (pero lírico) Eduardo Wilde, Amado Nervo y Rubén Darío, José Santos Chocano, Roberto Payró.

\section{Una demolición del estereotipo negativo}

La visita a Galicia, la inclusión de Galicia en su mapa español es una de las singularidades a destacar en la visita y el libro de Rojas. A diferencia de otros intelectuales contemporáneos, como Manuel Gálvez ${ }^{14}$ en El solar de la raza (1913), que no toma en cuenta esta región española, Rojas dedica varios capítulos a Galicia y a los intelectuales gallegos, para configurar la imagen de una "Galicia ilustrada" muy distante de los estereotipos inmigratorios. Este viraje es fundamental y afecta a la imagen toda de España, puesto que los españoles en general (como lo señalamos supra) permanecían subsumidos, para el imaginario argentino, para la "doxa" y el clisé', bajo el gentilicio de "gallegos" y los rasgos estereotípicos negativos a él asociados: "Ignorancia, brutalidad, suciedad, estrechez de criterio, fealdad y otras características negativas, se entrelazan en férreos lugares comunes que se vuelven muy difíciles de desactivar" (Lojo, 2008: 98-99). A principios del siglo XX, según consta en las memorias de Arturo Jauretche, los "gallegos" (o españoles), aunque considerados superiores a los nativos aborígenes y criollos, figuraban en los escalones más bajos de la axiología popular de la inmigración, que encumbraba, en cambio, a los anglosajones (por aquel entonces, además, los dueños del prestigioso ferrocarril, símbolo de todos los avances tecnológicos) (Lojo, ibíd.: 105-106, y 2007: 217-220).

$\mathrm{Su}$ genealogía de la ilustración gallega se remonta al padre Feijóo, "hombre excepcional por su curiosidad enciclopédica y su libertad de entendimiento" y también defensor de los criollos contra las teorías "degenerativas" que los consideraban inferiores a sus antepasados españoles. Recuerda asimismo Rojas que en la época independentista, "por odio de guerra, llamaron 'godo' al español y, después simplemente 'gallego', con intención despectiva" (296).

También son evocados en Retablo Español don Ramón del Valle Inclán y la Condesa de Pardo Bazán, ya mencionada. Describe a Valle Inclán, ante todo, como personaje excéntrico, abocado a cultivar su propia leyenda de iconoclasta. El juicio de Rojas sobre su obra destaca su poder renovador y atribuye sus méritos al carácter gallego, más que a rasgos estrictamente personales: "No ha creado ninguna fábula grande, no ha forjado ningún personaje universal, no ha revelado ninguna idea trascendente en sus símbolos; pero ha sido un reformador de la prosa española. Su ilustración no era muy vasta ni su cultura muy sólida. Su estilo proviene de su sensibilidad galaica; su arte es un eco del paisaje y los cantos de su tierra" (281).

Rojas entra y sale de España por Galicia, de tal modo que "Galicia aparece en el horizonte de estas memorias con la emoción alegre de la llegada y con la 'saudade' de

${ }^{14}$ A pesar de que con demasiada ligereza se suele meter a Gálvez y a Rojas en la misma bolsa, cabe destacar, entre otras distancias, el laicismo de Rojas frente al catolicismo militante de Gálvez, o las simpatías fascistas de este último escritor. Para el viaje español de Gálvez véase Quinziano (2005: http://www.canela.org.es/cuadernoscanela/canelapdf/cc17quinziano.pdf) 
la partida, en los dos extremos de mi itinerario español" (342). Le llaman la atención, ante todo, la belleza y la dulzura del paisaje, que "trasciende a la sensibilidad del gallego, fuerte en el trabajo y tierno en el amor. Comarca sensual y musical, sobre ella flotan el canto de la gaita y el dejo blando de su idioma" (343).

El profundo encanto "casi femenino" de esa tierra, retiene a los inmigrantes, como los que ve embarcándose con él rumbo a Buenos Aires mientras se despiden "con lágrimas en los ojos". Fiel a su mirada integradora, Rojas piensa en ellos como nuevos argentinos: "Dábanme ganas de decirles que ellos eran ya mis compatriotas. Venían a continuar la obra de los antepasados, y ellos son, también, en su anónima humildad, ministros de la historia; sus huesos serán mañana polvo de la Pampa, y en sus hijos retornará la vieja estirpe a nueva gloria" (345).

Un capítulo se consagra a los que Rojas llama "Caracteres del regionalismo gallego". Enumera aquellos "hombres y mujeres notables en arte, ciencia, política, armas y negocios" que han dado prestigio a Galicia. Habla del renacimiento de la lengua literaria y desde luego, de Rosalía de Castro, a la que califica como "voz ingenua" capaz de lirismo y también de iracunda protesta contra la injusticia. Si bien Rojas reconoce la monstruosidad del régimen feudal gallego y de los modernos sistemas centralistas, apunta la necesidad de distinguir al pueblo de Castilla (igualmente oprimido) del gobierno central.

Rojas define a Galicia por el paisaje y por el idioma. Es "un estilo de vida y de expresión", "una personalidad histórica", un pueblo con alma esencialmente lírica y romántica. Aunque corrobora la legitimidad de las reivindicaciones sustentadas por los galleguistas, no cree que Galicia tenga destino fuera de la unidad española, ya que caería en suma, bajo otra hegemonía: la de Portugal (347, 351-352). La solución, insiste, es construir un nuevo Estado español, regido sobre principios de justicia política y económica, y sobre el aceptación de las identidades históricas y culturales.

Si entender a España, concluye, es fundamental para Hispanoamérica (aun para esos afectados "argentinos en París" que describe con ironía), no menos importante es Hispanoamérica para España. "América es la creación más importante de la historia española y una explicación de su propio destino actual" (294). Sin embargo, subsiste el prejuicio colonial como "distraída omisión" -léase "ninguneo" - "de lo americano" (295). Españoles y argentinos se han despreciado demasiado tiempo mutuamente. Rojas adjudica esta actitud a la recíproca y sostenida ignorancia, que debe curarse por otros métodos que el de la "fraternidad retórica" (296). Un buen diagnóstico y una solución (el mutuo conocimiento) en la que ambas naciones todavía hoy se hallan empeñadas. 


\section{BIBLIOGRAFÍA}

ALBERDI, Juan Bautista.

1984 Fragmento preliminar al estudio del Derecho. Intr. y notas de Ricardo Grinberg. Buenos Aires: Biblos.

ARIAS SARAVIA, Leonor.

2000 La Argentina en clave de metáfora. Un itinerario a través del ensayo. Buenos Aires: Corregidor.

BERTONI, Lilia Ana.

2002 Patriotas, cosmopolitas y nacionalistas. La construcción de la nacionalidad argentina a fines del siglo XIX. Buenos Aires: F.C.E.

BIAGINI, Hugo.

2009 Identidad argentina y compromiso latinoamericano. Lanús: Universidad Nacional de Lanús, Colección Humanidades y Artes.

BORGES, Jorge Luis.

1974 "El escritor argentino y la tradición", en Discusión, en Obras Completas., Buenos Aires: Emecé, 1974, pp. 267- 274 [1ª ed. 1932].

GÁLVEZ, Manuel.

1913 El solar de la raza. Buenos Aires: Sociedad Cooperativa Nosotros.

GUTIÉRREZ, Juan María.

2006 "Cartas de un porteño. Carta al señor secretario de la Academia Española", en De la poesía y elocuencia de las tribus de América y otros textos. Sel., pról. y cron. de Juan G. Gómez García, bibliografía de Horacio Jorge Becco. Caracas: Biblioteca Ayacucho.

LOJO, María Rosa.

2004 "La raíz aborigen como imaginario alternativo", en Biagini, Hugo y Roig, Andrés (eds.). El pensamiento alternativo en la Argentina del siglo XX. Identidad, utopía, integración. Tomo 1: 1900-1930. Buenos Aires: Biblos, pp. 311-328.

2006 "Ricardo Rojas: en busca de la Historia perdida. La etapa del Centenario", Gramma, Año XVII, no 42/43, Abril-Octubre de 2006, Universidad del Salvador, pp. 16-24.

2007 "Las diversidades argentinas. Conflicto y armonías del multiculturalismo", Alba de América, vol. 26, no 49 y 50, julio de 2007: 285-301.

2007b "Los gallegos en la literatura argentina. Autobiografías y memorias", en Buenos Aires gallega. Inmigración, pasado y presente. Ruy Farías (ed.). Buenos Aires: Comisión para la Preservación del Patrimonio Histórico Cultural de la Ciudad de Buenos Aires, pp. 207-227.

2008 Los "gallegos" en el imaginario argentino. Literatura, sainete, prensa. María Rosa Lojo (dir.), en colaboración con Marina Guidotti de Sánchez y Ruy Farías. Coruña: Fundación Pedro Barrié de la Maza, 2008. 
2010 “Alberdi, el paradójico", en El pensamiento de Juan Bautista Alberdi. Buenos Aires: El Ateneo, 2010, pp. 9-22.

MANSILLA, Lucio Victorio.

1954 Mis memorias. Infancia-adolescencia. Estudio preliminar de Juan Carlos Ghiano. Buenos Aires: Hachette [1 ${ }^{\mathrm{a}}$ ed. 1904].

1963 "Los siete platos de arroz con leche" y "Académicos de número, honorarios, correspondientes y electos", en Entre-Nos. Causeries del Jueves. IV, Buenos Aires: Hachette: 86-101 y 479-486 [1 ${ }^{\text {a }}$ ed. 1889].

MASOTTA, Oscar.

1982 "Ricardo Rojas y el espíritu puro", en Conciencia y estructura. Buenos Aires: Corregidor, pp. 146-147

Moure, José Luis.

2008 "Dos perspectivas decimonónicas en la construcción de una identidad lingüística americana: Rufino José Cuervo y Juan María Gutiérrez", Conferencia plenaria, en III Jornadas de Español como Lengua Extranjera. I Congreso Internacional de Enseñanza e Investigación en ELSE. Universidad Nacional de Córdoba, Facultad de Lenguas. 21-23 de Mayo de 2008.

http://www.memorial.sp.gov.br/outros/palestra\%20j\%20s\%20moure/ Texto\%20J\%20L\%20Moure\%20Identidad\%20Linguistica\%20Ameri cana

MYERS, Federico.

2006 "Un autor en busca de un programa: Echeverría en sus escritos de reflexión estética", en Alejandra Laera y Martín Kohan (comps.). Las brújulas del extraviado. Para una lectura integral de Esteban Echeverría. Buenos Aires: Beatriz Viterbo, pp. 57-75.

QUINZIANO, Franco.

2005 "Miradas rioplatenses en los albores del siglo XX: Manuel Gálvez, viajero espiritual", Cuadernos CANELA (Confederación Académica Nipona, Española y Latinoamericana), vol. XVII, 125, 2005: 123141.

http://www.canela.org.es/cuadernoscanela/canelapdf/cc17quinziano.pdf

ROJAS, Ricardo.

1907 El alma española. Ensayo sobre la moderna literatura castellana. Valencia: Sempere.

1908 Cartas de Europa. Buenos Aires: M. Rodríguez Giles Editor.

1916 La argentinidad. Ensayo histórico sobre nuestra conciencia nacional en la gesta de la emancipación: 1810-1816. Buenos Aires: La Facultad.

1917 La literatura argentina. Ensayo filosófico sobre la evolución de la cultura en el Plata. Los gauchescos (1917), Los coloniales (1918), Los proscriptos (1920), Los modernos (1922). Buenos Aires: Imprenta Coni.

1924 La guerra de las naciones. Buenos Aires: La Facultad. 
1929 Elelín. Buenos Aires: La Facultad.

1935 Cervantes. Buenos Aires: La Facultad.

1938 Retablo español. Buenos Aires: Losada.

1939 Ollantay. Tragedia de los Andes. Buenos Aires: Losada.

1943 La salamanca. Buenos Aires: Losada.

1954 Blasón de plata. Buenos Aires: Losada [1 $\left.1^{\mathrm{a}} \mathrm{ed} .1910\right]$.

1960 Valoración social de las humanidades. Buenos Aires: Biblioteca del Colegio de Graduados de la Facultad de Filosofía y Letras.

1971 La restauración nacionalista. Pról. de Fermín Chávez. Buenos Aires: A. Peña Lillo Editor [1 $1^{\mathrm{a}}$ ed. 1909].

1980 Eurindia. Ensayo de estética fundado en la experiencia histórica de las culturas americanas. Pról. de Graciela Perosio, notas de Graciela Perosio y Nannina Rivarola. Buenos Aires, Capítulo: Biblioteca Argentina Fundamental, CEDAL [ $1^{\text {a }}$ ed. 1924].

SARMIENTO, Domingo Faustino.

1928 Condición del extranjero en América. Noticia Preliminar por Ricardo Rojas. Buenos Aires: La Facultad, 1928.

1953 Conflicto y armonías de las razas en América. Obras Completas. Tomo XXXVII y XXXVIII. Buenos Aires, Editorial Luz del Día.

1993 Viajes por Europa, África y América 1845-1847 y Diario de Gastos. Ed. de Javier Fernández. Buenos Aires, Colección Archivos [ $1^{\mathrm{a}}$ ed. en dos tomos, 1849 y 1851$]$.

UNAMUNO, Miguel de.

1977 "Domingo Faustino Sarmiento", Sur, n 341, julio-diciembre, 1977. WEINBERG, Félix.

1977 El Salón Literario de 1937. Buenos Aires: Hachette. 